\title{
latragenic injury to axillary artery: rescued by endovascular repair
}

\author{
Chih-Chen Kao, Yao-Kuang Huang \\ Division of Thoracic and Cardiovascular Surgery, Chiayi Chang Gung Memorial Hospital, Chiayi 613, Taiwan.
}

Correspondence to: Dr. Yao-Kuang Huang, Division of Thoracic and Cardiovascular Surgery, Chiayi Chang Gung Memorial Hospital, Chiayi 613, Taiwan. E-mail: cckaomd@gmail.com

How to cite this article: Kao CC, Huang YK. latragenic injury to axillary artery: rescued by endovascular repair. Vesse/ Plus 2018;2:18. http://dx.doi.org/10.20517/2574-1209.2018.42

Received: 4 Jun 2018 First Decision: 25 Jun 2018 Revised: 28 Jul 2018 Accepted: 30 Jul 2018 Published: 10 Aug 2018

Science Editor: Mario F. L. Gaudino Copy Editor: Jun-Yao Li Production Editor: Huan-Liang Wu

\begin{abstract}
Most of axillo-subclavian artery injuries are due to violence. latrogenic injuries to such vessels are relatively rare. We hereby present the first report of pigtail catheter insertion for right upper chest wall hematoma drainage resulting in penetration of axillary artery and pseudoaneurysm formation. A 39-year-old male victim of motor vehicle accident developed right upper chest wall hematoma after initial conservative treatment. Subsequent admission was arranged and pigtail catheter drainage was performed under sonography guidance. The procedure caused penetrating injury to his right axillary artery with pseudoaneurysm formation. Endovascular repair and stent placement were performed. The patient was discharged within 2 weeks without significant sequelae. Non-catheterization procedure caused penetration of axillary artery was rarely seen in published reports. Our report described a case of axillary artery penetration resulted by pigtail catheter insertion which was never seen. We wish to emphasize on the jeopardy of non-vascular procedure on penetrating nearby vessels because of anatomical proximity.
\end{abstract}

Keywords: Trauma, vascular injury, endovascular surgery

\section{INTRODUCTION}

Thoracic cage and shoulder girdle provide a well protection of the proximate major vessels. Therefore, injuries to such vessels which are adjacent to thoracic inlet, including axillo-subclavian artery are fairly rare ${ }^{[1]}$. On the other hand, the well protection of these vessels by local anatomy also posed a challenge for surgeons to approach them during open surgery. The rareness of such cases further increases the risk of open operation of axillo-subclavian vessel repair due to inexperience of even senior cardiovascular surgeons. Stab and gunshots are among the majority of mechanism causing injuries to axillo-subclavian artery ${ }^{[2]}$. Iatrogenic injuries are relatively minor in proportion ${ }^{[3]}$. Overall mortality of patients with axillo-subclavian artery injury

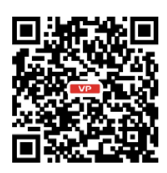



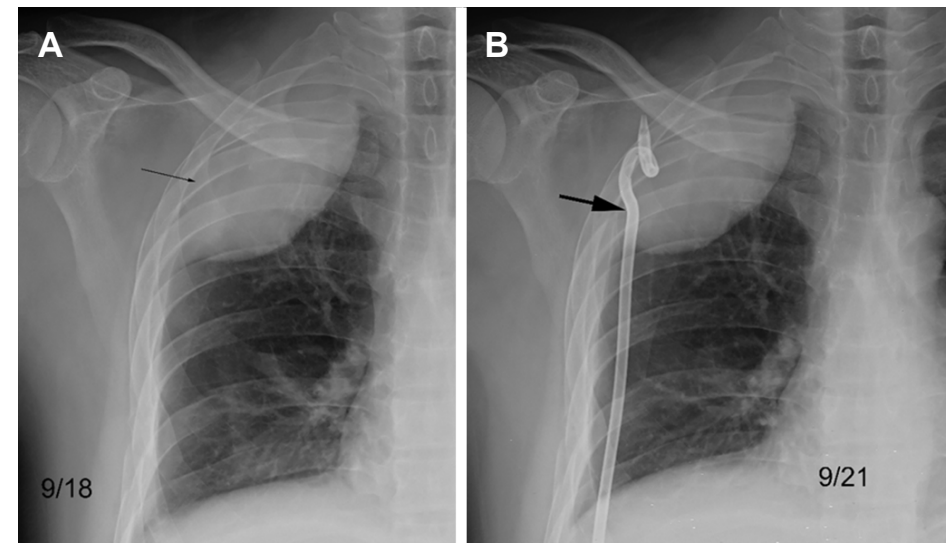

Figure 1. (A) Chest $X$-ray image reveals a huge hematoma or haemothorax shadow which crosses as many as 4 intercostal spaces. (B) The arrow points out the insertion site of the pigtail tube, which is very close to axillary artery

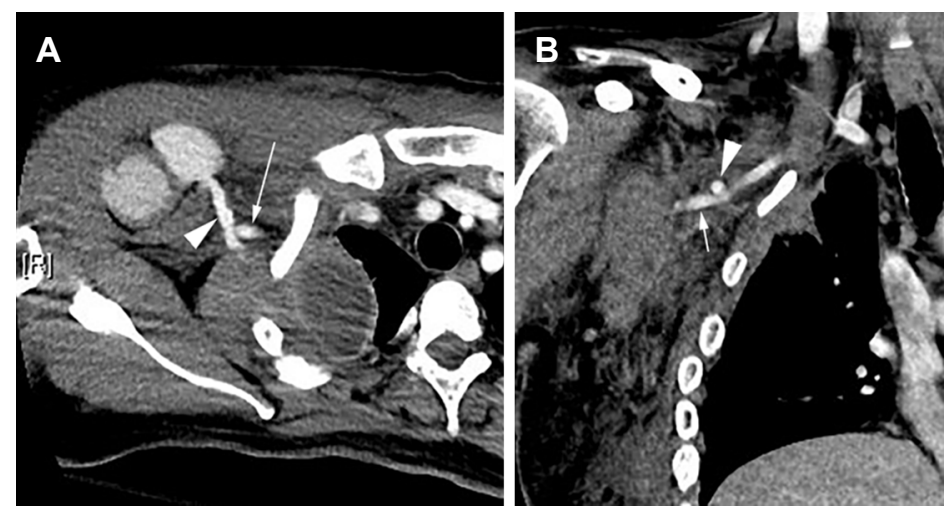

Figure 2. (A) Contrast-enhanced chest CT axial view reveals the penetrated axillary artery (arrow) and a track (arrowhead) tracing to the pseudoaneurysm. (B) Coronal view of the same lesion

who survived initial insult and reached the medical institutes receiving operation range from $5 \%$ to $30 \%{ }^{[4-6]}$. As a result, a growing trend of endovascular procedure for repairing injuries to axillo-subclavian artery appears in recent years ${ }^{[3]}$. We herein present a case of penetrating injury to the right axillary artery resulted by pigtail catheter insertion. The patient was successfully treated with endovascular repair and discharged within 2 weeks without significant sequelae.

\section{CASE REPORT}

A 39-year-old male patient, victim of a motor vehicle accident, was admitted to our satellite hospital. Right 1st and 3rd -8th ribs fracture, minimal pneumothorax and right pleural effusion were diagnosed by chest computed tomograms (CT). Right upper chest wall hematoma was found in subsequent out-patient clinic follow up with CXR. He was then admitted, and thoracocentesis under sonography guidance was done. Grossly, the drainage fluid was bloody, which was suspected to be the result of musculoskeletal hemorrhage. Progressive chest pain with expansion of chest wall ecchymosis developed after driange, and therefore a pigtail catheter with $12 \mathrm{Fr}$. in diameter was inserted for drainage over right upper chest wall [Figure 1]. Nonetheless, the drainage amount was minimal and it was considered as a failure because the amount of pleural effusion remained unchanged on chest X-ray. The pigtail catheter was removed within 3 days of placement. However, upon removal, the doctors encountered major bleeding, up to $2000 \mathrm{cc}$. Emergent CT scan was done right after the incidence which illustrated contrast extravasation trace from right axillary artery leading to the tract of the previous inserted pigtail catheter, and the formation of a chest wall pseudoaneurysm [Figure 2]. General surgeons tried to approach the bleeder with open surgery but failed. The patient was then transferred to our hospital. 

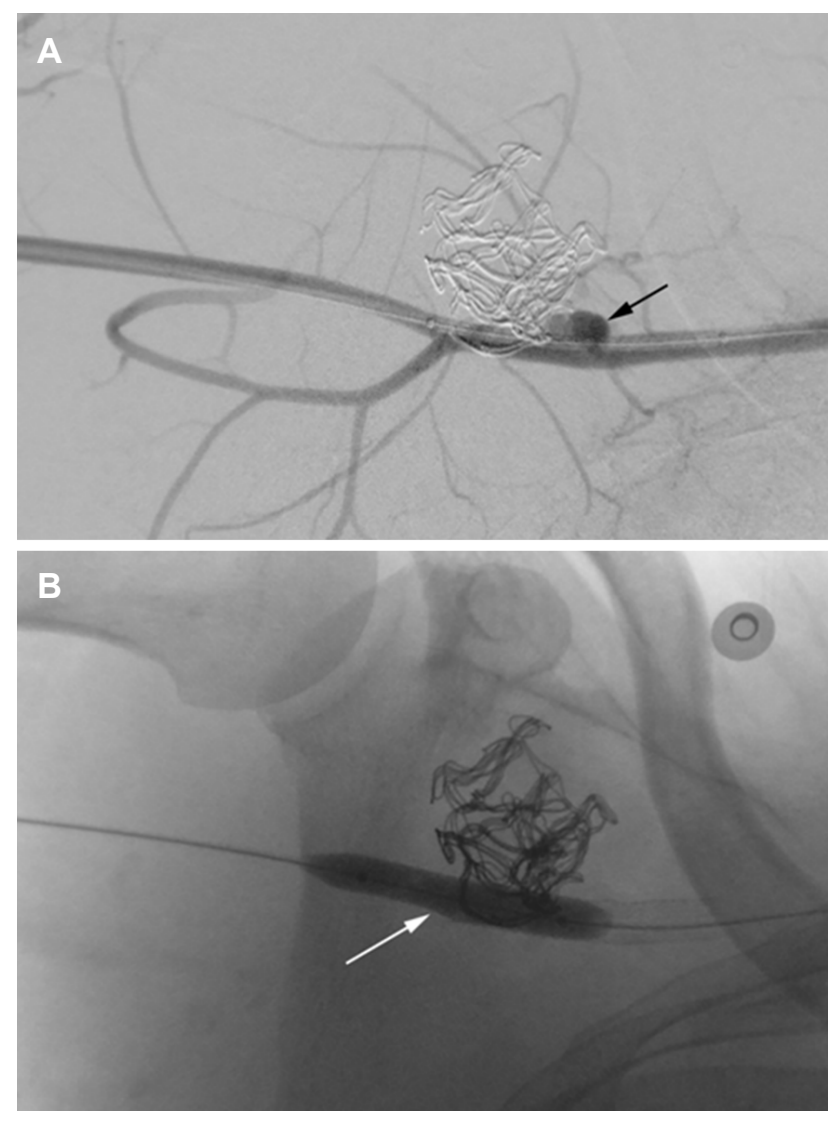

Figure 3. (A) Angiography shows the pseudoaneurysm formation. (B) The endoprosthesis (GORE ${ }^{\circledR}$ VIABAHN® Endoprosthesis, W.L. Gore and Associates, Inc. Flagstaff, AZ)

Right on transferal, emergent endovascular repair was scheduled, and an extravasation of contrast media was detected on right axillary artery intra-operatively. A cover stent (GORE ${ }^{\bullet}$ VIABAHN $^{\circledR}$ Endoprosthesis, W.L. Gore and Associates, Inc. Flagstaff, AZ) with $8 \mathrm{~mm}$ in diameter and $5 \mathrm{~cm}$ in length was implanted through right brachial artery to facilitate arterial repair. Postdilatation was done with Rival $8 \mathrm{~mm}$ balloon. The pseudoanerysm was debrided after the endovascular procedure [Figures 3 and 4]. The patient was discharged uneventfully within 2 weeks.

\section{DISCUSSION}

The complexity of anatomical structure of axillo-subclavian artery poses a potential risk for open surgical approach. Not to mention that injuries of axillo-subclavian artery are uncommon, and therefore even seasoned surgeons have limited experience on approaching the field under active bleeding condition ${ }^{[4]}$. Furthermore, the patients who suffer from such injuries might be too critically ill and thus not suitable for highly invasive treatment ${ }^{[7]}$. Under such circumstances, there is a growing trend of endovascular repair in axillosubclavian artery injuries ${ }^{[3,7-10]}$. Among such cases, iatrogenic-related injury accounts for $22.4 \%$. Most of the iatrogenic-related penetrating injuries of axillo-subclavian arteries cases are caused by venous catheteriza$\operatorname{tion}^{[3]}$. Iatrogenic-related penetrating injuries to axillo-subclavian artery result in complications such as pseudoaneurysm, AV fistula and dissection ${ }^{[3,11-13]}$.

Our case was rare, and there was no similar report in previous publication. It was a case of penetrating injury to axillary artery by pigtail catheter insertion for chest wall hematoma. Pseudoaneurysm formation was revealed with subsequent CT and angiogram evaluation. For injuries to the axillo-subclavian artery, there were various kinds of endoprosthesis useful for repair. For the subgroup of penetrating injuries or iatrogenic 


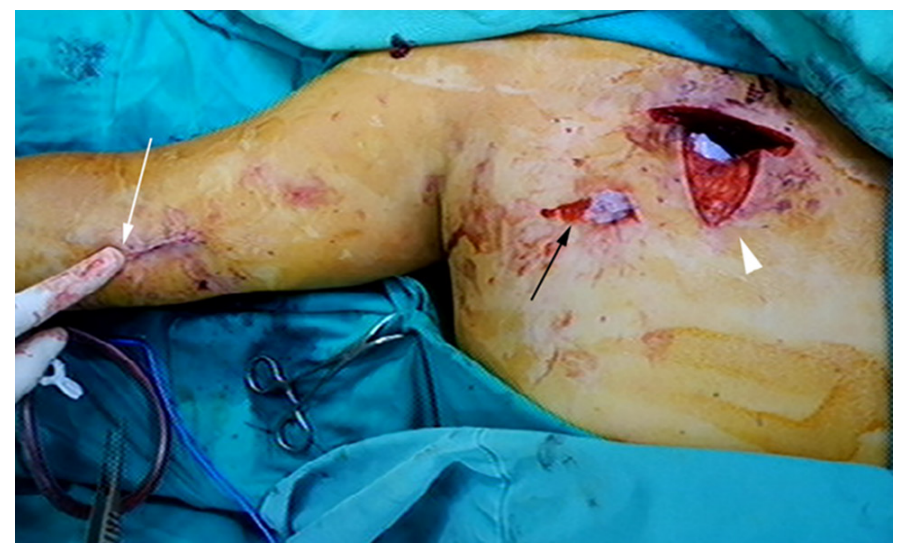

Figure 4. The wound of the patient. The white arrow points out the approach site of endovascular procedure which is the brachial artery near elbow. The black arrow is the insertion site of the pigtail tube while the white arrowhead points out the wound created by the surgeon at our satellite hospital in attempt to approach the bleeder

injuries to axillo-subclavian artery, there were very few cases repaired by endoprosthesis (GORE VIABAHN $^{\circledR}$ Endoprosthesis, W.L. Gore and Associates, Inc. Flagstaff, AZ) that we chose for our patient ${ }^{[3,8,14,15]}$.

Based on what was mentioned above, we wish to deliver a few messages. First of all, there is a potential risk of non-vascular procedure in causing axillary artery penetrating injury. In trauma such as our case, the site of hematoma was at upper chest which was very close to axillo-subclavian artery anatomically. When approaching the lesion with percutaneous procedures such as pigtail catheter drainage, penetrating injury could happen.

Secondly, we also demonstrated the safety and instantaneity of endovascular repair in case of penetrating axillo-subclavian artery with ruptured pseudoaneurysm. As mentioned above, the complexity of anatomical structure over axillo-subclavian artery makes it difficult to approach the vessels openly. While patients with such injuries might be too critically ill, open surgery might not be able to provide timely repair. In comparison, endovascular has the potential to provide a safer, quicker and more secure approach to repair of penetrating injuries to axillo-subclavian artery.

\section{DECLARATIONS}

\section{Acknowledgments}

Lu MS, Lin CC, Tseng YH helped to proofreading the draft.

\section{Authors' contributions}

Drafted the manuscript, and collected the proper images: Kao CC

Conceived of the study and helped to proofreading the draft: Huang YK

Read and approved the final manuscript: both authors

\section{Availability of data and materials}

The data in the study was collected from the medical record of the patient in Chiayi Chang Gung Memorial Hospital. The patient has agreed to provide his data for study.

\section{Financial support and sponsorship}

Huang YK has sources of funding including research number CMRPG380841, CMRPG6C0342, CMRPG6B0503, NMRPG6D022, CMRPG6E0421. 


\section{Conflicts of interest}

All authors declare that there are no conflicts of interest.

\section{Ethical approval and consent to participate}

The patient has agreed to provide his data for study.

\section{Consent for publication}

Written informed consent was delivered to the patient and was signed by the patient himself. The patient was well explained and was aware of the publication of this case report and any accompanying images.

\section{Copyright}

(c) The Author(s) 2018.

\section{REFERENCES}

1. Demetriades D, Chahwan S, Gomez H, Peng R, Velmahos G, Murray J, Asensio J, Bongard F. Penetrating injuries to the subclavian and axillary vessels. J Am Coll Surg 1999;188:290-5.

2. Gill H, Jenkins W, Edu S, Bekker W, Nicol AJ, Navsaria PH. Civilian penetrating axillary artery injuries. World J Surg 2011;35:962-6.

3. DuBose JJ, Rajani R, Gilani R, Arthurs ZA, Morrison JJ, Clouse WD, Rasmussen TE; Endovascular skills for trauma and resuscitative surgery working group. Endovascular management of axillo-subclavian arterial injury: a review of published experience. Injury 2012;43:1785-92.

4. Demetriades D, Asensio JA. Subclavian and axillary vascular injuries. The Surg Clin North Am 2001;81:1357-73, xiii.

5. Schaff HV, Brawley RK. Operative management of penetrating vascular injuries of the thoracic outlet. Surgery 1977;82:182-91.

6. Degiannis E, Levy RD, Potokar T, Saadia R. Penetrating injuries of the axillary artery. Aust N Z J Surg 1995;65:327-30.

7. Chemelli AP, Wiedermann F, Klocker J, Falkensammer J, Strasak A, Czermak BV, Waldenberger P, Chemelli-Steinguber IE. Endovascular management of inadvertent subclavian artery catheterization during subclavian vein cannulation. J Vasc Interv Radiol 2010;21:4706.

8. Pikwer A, Acosta S, Kolbel T, Malina M, Sonesson B, Akeson J. Management of inadvertent arterial catheterisation associated with central venous access procedures. Eur J Vasc Endovasc Surg. 2009;38:707-14.

9. Kumar RM, Reddy SS, Sharma R, Mahajan R, Talwar KK. Endovascular repair of a traumatic axillary artery pseudoaneurysm. Cardiovasc Intervent Radiol 2009;32:598-600.

10. Michaluk BT, Deutsch E, Moufid R, Panetta TF. Endovascular repair of an axillary artery pseudoaneurysm attributed to hyperextension injury. Ann Vasc Surg 2009;23:412 e415-9.

11. Criado E, Marston WA, Ligush J, Mauro MA, Keagy BA: Endovascular repair of peripheral aneurysms, pseudoaneurysms, and arteriovenous fistulas. Ann Vasc Surg 1997;11:256-63.

12. Kapadia S, Parakh R, Grover T, Agarwal S, Yadav A. Endovascular covered stent for management of arterial pseudoaneurysms after central venous access. J Cardiothorac Vasc Anesth 2007;21:99-102.

13. Castelli P, Caronno R, Piffaretti G, Tozzi M, Lagana D, Carrafiello G, Cuffari S. Endovascular repair of traumatic injuries of the subclavian and axillary arteries. Injury 2005;36:778-82.

14. Vinces FY, Sperling DC. Endovascular treatment of a combined pseudoaneurysm and arteriovenous fistula of the subclavian artery caused by a gunshot wound to the chest. J Thorac Cardiovasc Surg 2005;130:225-7.

15. Chen AY, Laniado I Jr, Lin PH. Durability of the Viabahn stent graft after axillary artery pseudoaneurysm exclusion. J Vasc Surg Cases Innov Tech 2017;3:99-101. 